\title{
Introduction: Evolutionary methodologies for analyzing environmental innovations and the implications for environmental policy
}

\author{
Koen Frenken ${ }^{\mathrm{a}, *}$, Albert Faber ${ }^{\mathrm{b}, 1}$ \\ a Section of Economic Geography, Urban E' Regional research centre Utrecht (URU), Utrecht University, P.O. Box 80115, 3508 TC Utrecht, The Netherlands \\ ${ }^{\mathrm{b}}$ Netherlands Environmental Assessment Agency (MNP), P.O. Box 303, 3720 AH Bilthoven, The Netherlands
}

\section{A R T I C L E I N F O}

\section{Article history:}

Received 15 April 2008

Received in revised form 22 April 2008

Accepted 22 April 2008

\section{Introduction}

It is commonly recognized that environmental innovations provide an important key to sustainability. However, the two dominant approaches within environmental economics - neoclassical and ecological economics - have found it difficult to develop a systematic research program on environmental innovation. From the 1980s evolutionary economics emerged as a framework for analysing analyzing and understanding economic change and industrial dynamics. Evolutionary economic theory provides a dynamic framework, where differential patterns of survival in populations produce aggregate changes in an economy [1]. From the mid-1990s onwards, evolutionary economics emerged as a promising alternative for the economic analysis of environmental innovations. More recently, scholars have started to develop formal evolutionary models in environmental studies. These efforts reflect a further deepening of the evolutionary program in the area of environmental studies, which opens up possibilities for applications in environmental policy-making [2,3].

The goal of this special issue is to provide an overview of evolutionary approaches to environmental innovation with a focus on formal modeling. We consider the recent modeling efforts as a next step towards a truly "evolutionary environmental economics". Such an approach provides policymakers with an alternative perspective on environmental policy, emphasizing the dynamic welfare effects of policy [4], the dangers of technological lock-in [5], co-evolutionary perspectives on technical change [6,9], consumer preferences [7] and long-term transition policy [3], often (but not exclusively) by means of scenario analysis or dynamic simulation models. This puts the evolutionary perspective as complementary to neoclassical policy insights that are highly appropriate for well-defined, short-term problem contexts and to ecological policy insights into the management of material flows.

The contributions to the special issue are divided into three parts. The first part consists of a methodological discussion and a literature review, and serves as an introduction to the use of evolutionary economics in environmental studies and environmental policy. The second part consists of seven modeling contributions addressing a variety of topics, including technology diffusion, technological substitution, consumer heterogeneity, eco-labelling, renewable resources, and recycling. The third part contains two empirical contributions on innovation systems, applied to a specific sector (automotive) and particular emerging technologies (biofuels and biomass).

\footnotetext{
* Corresponding author. Tel.: +31302532466.

E-mail addresses: k.frenken@geo.uu.nl (K. Frenken), albert.faber@mnp.nl (A. Faber).

1 Tel.: +310302743683.
} 


\section{Part 1: Methodological discussions on evolutionary environmental economics}

Verspagen discusses the methodological foundations of evolutionary models in the context of environmental policy. He argues that the empirical and policy relevance of such models is greatly enhanced if applied to technologies that compete at the mesolevel of particular economic sectors and if calibrated with reliable technical information. The evolutionary dynamics of technology adoption driven by increasing returns and heterogeneous demand provides information about the likelihood of technological substitution processes under different future scenarios and policy regimes. As such, evolutionary models provide a supplement to macro-economic (general equilibrium) models.

The paper by Faber and Frenken focuses on the relevance of evolutionary modelling for environmental policy. They identify three promising areas where evolutionary modelling could have significant added value for environmental policy-making. The first application relates to the static and dynamic analysis of welfare effects of environmental innovation, by distinguishing effects on the environment, on innovation and on competition. The second area of application regards the analysis of conditions affecting technological transitions and the implications for public policy. Here, the roles of variety and flexibility are highlighted, as well as the importance of niches and protected environments for infant technologies. Third, evolutionary models are particularly useful in the analysis of social dynamics, heterogeneity of preferences and the effects on consumer demand, which opens opportunities for framing more advanced environmental consumer policy.

\section{Part 2: Evolutionary economic models and environmental policy}

Brouillat presents a model of product innovation and industrial dynamics, much in the tradition of the vintage evolutionary models of Nelson and Winter [1]. Innovation is defined as an increase in either a product's recyclability or in product lifetime. This paper presents a classic evolutionary model of industrial dynamics, which extends to incorporate the use and re-use of resources in the production process, thus expanding the economic scope to include environmental effects. From an environmental point of view, the diffusion of such 'green' products will reduce both waste flows in the economy and pressure on virgin resources. The results suggest introducing regulation policies aimed at encouraging firms to invest in both product recyclability and lifetime in order to benefit from their complementarities. Results also show that government better direct environmental policies on firms' environmental innovation strategies than on demand attributes because significant changes in these strategies would provide much more radical environmental changes.

The contribution by Cantono and Silverberg further develops a model of technology diffusion based on percolation theory from physics, which can be used to model diffusion as a process of contagion within social networks of consumers with heterogeneous reservation prices for adoption. By combining this with the positive feedback from increasing returns to aggregate adoption, a threshold emerges for the widespread diffusion of environmental technologies whose upfront costs are initially too high. The use of temporary subsidies may allow this threshold to be jumpstarted. The exact amount and time span of subsidy required to trigger diffusion is shown to depend on the learning curve parameter, for which there is a window of policy leverage.

The paper by Schwarz and Ernst presents an agent-based model of the diffusion of water-saving innovations. An important contribution of this model is the exploitation of empirical data on the spatial distribution of technologies and on lifestyle-related preferences as derived from surveys. Incorporating empirical data in agent-based modelling has been recognized as problematic [8], issues which are tackled in this model by focusing on calibration of the models as well as validation of the modelling results. The simulation exercise shows that water-saving innovations will most likely diffuse without further promotion. The simulation also examines the use of differentiated promotion strategies that relate specifically to both innovations and lifestyles.

Bleda and Valente develop a demand-oriented model, exploring the effect on innovation by providing consumers with information on the environmental impact of products by means of eco-labelling. The model studies three schemes: no eco-labels, binary eco-labels and graded eco-labels. It is argued that the absence of eco-labels provides no incentive for innovation in an environmental direction, while binary labels provide this incentive only until the threshold value for labeling is reached. A graded eco-labelling scheme generally provides incentives to maintain environmental innovative activities, because the environmental dimension of products can no longer be ignored by firms. Characteristics of products for the mainstream consumer market are available to ever more firms, giving firms with environmental innovative activities a competitive edge. This paper explores the effect of consumer decisions on environmental innovativeness in situations where the environmental aspect of purchasing is secondary to other issues like price and general quality. It shows that firms can stay competitive by improving the environmental score of there products, which addresses a niche market of environmentally conscious consumers in the case of binary eco-labels, but a significant market share in the case of graded eco-labels.

The model presented by Boschetti and Brede explores harvesting strategies when a number of agents compete for a limited renewable resource. They present a model of interacting agents, who choose among alternative strategies of resource exploitation, aiming to minimize shared resources with other agents. This game-theoretic paper finds that for scarce resources a purely competitive, greedy strategy outperforms a collaborative approach, while the opposite holds for more abundant resources. This approach can be used to monitor the status of a resource, but it may also be used for developing policy for the management of scarce resources. This approach is novel in the way the results of harvesting scenarios are used to monitor the resource status for management purposes and is effective in both centralised and decentralised decision making.

Windrum, Ciarli and Birchenhall develop a model of technological transitions from a dominant technological paradigm to a 'green' technological paradigm. Their work has been divided into two separate papers. In the first paper, the emphasis lies on 
consumer heterogeneity of preferences with regards to environmental pollution and the environmental impact of the products they consume. In contrast to other models, and in line with historical evidence on paradigm shifts, the authors specify how technological change can trigger the development and diffusion of new preferences. The change in demand in turn affects the feasibility of later technological paradigms. The model results show that, given the co-evolution of consumer preferences and technological change, sufficient numbers of environmentally concerned consumers can stimulate the development and diffusion of greener technologies.

In their second paper, Windrum, Ciarli and Birchenhall qualify the findings of the first paper by focusing on trade-offs between price, quality and environmental impact. Here they show that despite the possibility that consumers may change their preferences in favour of products with lower environmental impact, the co-evolutionary dynamics between technological change and consumer demand may well lead to a bifurcation of the market into two distinct niches. In one niche, firms specialize on reducing the environmental impact of product, while in the other niche firms focus on reducing cost or on improving quality. The net result is a high level of pollution despite the emergence of a niche for green products. The authors therefore conclude that the existence of a group of environmentally conscious consumers creating a niche, is not a sufficient condition to trigger a comprehensive paradigm shift towards green technologies.

\section{Part 3: Empirical approaches on innovation systems}

A specific empirical strand in evolutionary economics is based on the concept of Innovation Systems, which can be defined as the set of interacting actors and institutions that influence the rate and direction of an innovative process. The concept was initially applied to national levels [10,11], but presently extents to the study of sectoral and technological innovation systems as well. The paper by Oltra and Saint-Jean develops a framework for a sectoral system of innovation in order to analyze the dynamics of environmental innovation. In doing so, they extend earlier work on sectoral systems and the notion of technological regime [12], to incorporate system features that are especially relevant to environmental innovation policy. In particular, they distinguish between the technological regime, demand conditions, and government policy, and highlight the co-evolving nature of the dynamics in the three subsystems. Their application to the French automotive industry illustrates the dynamics in which technologies, institutions and industry structure co-evolve within the dominant technological paradigm of the internal combustion engine. They also show how the current demand conditions are unfavourable for the exploration of alternative trajectories, suggesting the need for more active demand policies. The study not only provides an integrated analysis of the dynamics of environmental innovation in the French automotive industry, but also a framework that is sufficiently general to be applied to other sectors where environmental innovation plays an important role.

Hekkert and Negro use a technological innovation system approach [13] in their analysis of emergent sustainable energy technologies. Their paper provides a comparative summary and discussion drawing on five case studies in the area of biomass and biofuels. Innovation in these emerging technologies can be assessed as the interaction between technological development and the technological innovation system. The authors distinguish seven specific functions of a technological innovation system: entrepreneurial activities, knowledge development, knowledge diffusion, guidance of search, market formation, resource mobilisation and the formation of advocacy coalitions. The authors show that all functions need to be satisfied for a good performance of the innovation system and that, particularly the market formation function drives positive feedback cycles accelerating the rate of innovation. This study offers a very structured way to show innovation patterns, most specifically when dealing with interactions between functions in terms of virtuous and vicious cycles. As such, the authors provide a more dynamic approach to the otherwise static framework of innovation systems.

Evolutionary economics provides a systematic framework for analyzing many facets of environmental innovation. Both the modeling and the empirical contributions reflect the versatility of an evolutionary approach in addressing social, economic and political mechanisms that apply in the specific setting of an environmental problem. The policy implications that can be drawn from evolutionary studies are more long-term and, consequently, often rather impressionistic. As such, insights from evolutionary models are complementary to neoclassical policy insights that apply well to well-defined, short-term problems.

We consider the recent modeling efforts as a next step towards a truly "evolutionary environmental economics". We are convinced that with further methodological advances in modeling - including game theory, network theory and agent-based modeling - an increasing number of evolutionary models will come available for policy use in the area of research policy, environmental innovation and environmental technology diffusion. Combined with the increased availability of high-quality datasets on technological characteristics and consumer preferences to calibrate the models for application to specific contexts, these models provide a welcome supplement to existing models and, potentially, an important input to the environmental policymaking process.

\section{References}

[1] R. Nelson, S.G. Winter, An Evolutionary Theory of Economic Change, Belknap Press of Harvard University Press, London, 1982.

[2] K. Frenken, A. Faber, A.M. Idenburg, Introduction: environmental policy and modelling in evolutionary economics, in: A. Faber, K. Frenken, A.M. Idenburg (Eds.), Environmental Policy and Modelling in Evolutionary Economics, MNP (report 550033001), Bilthoven, 2006, pp. 11-18.

[3] J.C.J.M. van den Bergh, A. Faber, A.M. Idenburg, F.H. Oosterhuis, Evolutionary Economics and Environmental Policy. Survival of the Greenest., Edward Elgar, Cheltenham, 2007.

[4] A. Faber, K. Frenken, Models in evolutionary economics and environmental policy: Towards an evolutionary environmental economics, Technol. Forecast. Soc. Change (2008), doi:10.1016/j.techfore.2008.04.009.

[5] G.C. Unruh, Escaping carbon lock-in, Energy Policy 30 (2002) 317-325. 
[6] J.C.J.M. van den Bergh, S. Stagl, Coevolution of economic behaviour and institutions: towards a theory of institutional change, J. Evol. Econ. 13 (2003) $289-317$.

[7] M.A. Janssen, W. Jager, Stimulating diffusion of green products, co-evolution between firms and consumers, J. Evol. Econ. 12 (2002) $283-306$.

[8] P. Windrum, G. Fagiolo, A. Moneta, Empirical validation of agent-based models: alternatives and prospects, Journal of Artificial Societies and Social Simulation 10 (2007) 8.

[9] P. Windrum, C. Birchenhall, Structural change in the presence of network externalities: a co-evolutionary model of technological successions, J. Evol. Econ. 15 (2005) 123-148

[10] B.A. Lundvall, National Systems of Innovation - Towards a Theory of Innovation and Interactive Learning, Pinter publishers, London, 1992.

[11] R. Nelson, National innovation systems - a comparative analysis, Oxford University Press, New York/Oxford, 1993.

[12] F. Malerba, Sectoral systems of innovation and production, Res. Policy 102 (2002) 845-859.

[13] M.P. Hekkert, R.A.A. Suurs, S.O. Negro, S. Kuhlmann, R.E.H.M. Smits, Functions of innovation systems: a new approach for analysing technological change, Technol. Forecast. Soc. Change 74 (2007) 413-432.

Albert Faber works as a policy researcher for the Netherlands Environmental Assessment Agency (MNP) on environmental policy and technological development. His research interests include evolutionary economics, environmental innovations, transition policy and systems of innovation. He studied environmental sciences at Wageningen Agricultural University.

Koen Frenken studied economics at the University of Amsterdam. He holds a Ph.D. jointly awarded in 2001 by the University of Grenoble (in applied economics) and the University of Amsterdam (in social sciences). He is currently an Associate Professor in Economic Geography at the Faculty of Geosciences at Utrecht University and a member of the Urban and Regional research centre Utrecht (URU). His research interests include evolutionary economics, complexity theory, science studies, innovation studies, environmental studies and economic geography. 